\title{
STORIES E SEUS CONSTRUTOS DE TEMPORALIDADE: a presentificação de um passado recente
}

\author{
Lorena Risse ${ }^{1}$
}

Resumo: O artigo tem como foco traçar apontamentos sobre a constituição de temporalidades próprias das novas mídias, construtos midiáticos de tempo que alimentam e movimentam o funcionamento de espaços imagéticos específicos, que têm protagonizado novas tendências comunicacionais. Trazemos para o centro do debate o conceito de efemeridade vendo-o enquanto qualidade presente nas narrativas contemporâneas sobre o cotidiano, acompanhado de materiais empíricos nos quais o devir se faz presente de forma material, através de elementos na interface e na superfície da imagem, que é essencialmente efêmera. Criando imagens com marcas temporais tão fortes, como uma vida útil de 24 horas, uma duração limitada de captação e exibição, entre outras, estas iniciativas colocam-se numa linha de frente de serviços que se pautam cada vez mais na experiência imagética única, do que relações de permanência e de eterno retorno ao arquivo.

Palavras-chave: Temporalidades, stories, construto, efemeridade.

\begin{abstract}
The article focuses on the constitution of temporalities proper to the new media, media constructs of time that feed and move the functioning of specific imagery spaces, which has led to new communication tendencies. We bring to the center of the debate the concept of ephemerality, seeing it as a quality present in contemporary narratives about everyday life, accompanied by empirical materials in which the tendency becomes materially present through elements on the interface and on the surface of the image, which is essentially ephemeral. Creating images with such strong time stamps, such as a 24-hour shelf life, limited exhibition, among others, these initiatives are placed in a front line of services that is based more and more on the unique imagery experience, than relations of permanence and the eternal return to the archive.
\end{abstract}

Keywords: Temporalities, stories, construct, ephemerality.

\section{Introdução}

Este artigo tem como foco traçar apontamentos sobre como são formados alguns construtos de tempo nas novas mídias, essencialmente no território imagético, que surgem com uma proposta pautada na qualidade efêmera da comunicação. Estas construções midiáticas reconfiguram noções de presente e passado que ficam evidentes em práticas comunicacionais e nos próprios meios que as abrigam. O ponto de partida para essa proposta se deu com o contato com uma tendência imagética em específico, que nos deu pistas, por vezes nítidas e por vezes desfocadas, sobre um possível estabelecimento de um regime que cria e incita um modo de perceber a passagem do tempo e registrá-lo, um modo efêmero. No

\footnotetext{
${ }^{1}$ Jornalista, Mestra em Comunicação e Informação pela Universidade Federal do Rio Grande do Sul, doutoranda do PPG em Ciências da Comunicação na Universidade do Vale do Rio dos Sinos. Bolsista Capes.
} 
início da segunda década dos anos 2000, foi notável uma gradativa solidificação de uma tendência comunicacional que presava por uma produção de conteúdo mais acelerada, feita, principalmente, a partir de dispositivos móveis e que ficou conhecida como formato Stories. O investimento de atenção para esse tipo de produção, levou-nos a entendê-la como um construto midiático próprio do nosso tempo e que revelava aspectos essenciais da forma de comunicar contemporânea, que passa também por práticas efêmeras e de reconfiguração do que se entende como passado.

Tendo esse fato como o grande convocador de reflexões, começamos nosso primeiro acionamento teórico vem com o prognóstico de Jean Baudrillard, feito em meados de 1980, sobre o que ele chamou de êxtase da Comunicação. Tratava-se de um cenário que seria alcançado quando o foco das atenções sociais passasse dos grandes personagens midiáticos, para os sujeitos comuns e suas operações íntimas e cotidianas, abalando certezas e modos de comunicar já consolidados. Segundo o autor, a estabilização e o gradativo consumo dessa angulação comunicacional estariam ligados ao movimento tecnológico de expansão dos dispositivos de visibilidade, que se realizaria com a proliferação de telas alocadas em diversos pontos espaciais das cidades, cada uma desenvolvendo um papel mediador frente a quantidade expressiva de informações geradas por estes novos produtores amadores.

O prognóstico de Baudrillard pode ser visto como um diagnóstico preciso do que temos atualmente como parte importante do regime comunicacional ocidental que, segundo J. Macgregor Wise (2012), foi impulsionado pela dissolução dos polos produtivos únicos de informação e por uma dispersão de vozes ativas na geração de dados. Essa configuração produziu um volume expressivo de informações geradas por sujeitos comuns e que constituem grande parte do fluxo da internet. Esse montante significativo, advém do estabelecimento de um processo gradual de vínculo entre humano e máquina, como previsto por Baudrillard, e que se realiza a partir do cultivo e estímulo de um desejo em particular, o de estar ininterruptamente conectado com algo, dando vida ao que Wise (2012) chama de contato perpétuo. A intensidade das palavras utilizadas nesse conceito nos impressionou logo de partida, já que o significado de perpétuo é exatamente algo que dura e que tem sua continuidade estendida ao eterno e, de fato, uma das coisas que pode ser vista como duradoura nessa paisagem contemporânea comunicacional é exatamente a relação entre homem e tecnologia, homem e técnica, enquanto que os produtos desse enlace são, paradoxalmente, cada vez mais, feitos para sumir, desaparecer. 
Por meio dessa ligação, os sujeitos são convidados a entrar em uma incansável corrida por territórios e serviços que possibilitem o armazenamento e o compartilhamento de informações que, como dissemos, compõem uma camada importante do fluxo de dados da internet. Esses espaços foram radicalmente transformados pelas possibilidades que a comunicação ubíqua passou a oferecer, e popularizaram o que o autor chama de "agora compartilhado" (WISE, 2012), um construto de temporalidade comum às novas mídias, engendrado nos meandros da constituição da instantaneidade dos processos comunicacionais, como moeda de grande impacto comercial e social. Em outras palavras, há um nicho mercadológico interessado em produzir e incentivar o consumo informacional que possua essa característica, essa tendência singular, que demarca o interesse intenso pela temporalidade dos acontecimentos, pela proximidade com um possível presente e pela volatilidade da informação, e é sobre ele que debruçaremos nossa atenção na elaboração deste artigo.

Esse é o cenário em que formatos comunicacionais efêmeros surgem e que funcionam aqui como imagens-fagulha, ou seja, imagens de afecção primeira, que catapultaram nosso ímpeto questionador. A primeira experiência empírica que ressaltamos se deu com produções feitas para uma iniciativa em especial, o Snapchat, aplicativo criado em 2011 por quatro estudantes da Stanford University, Evan Spiegel, Bobby Murphy e Reggie Brown, disponibilizado gratuitamente pelas plataformas Android, Apple e Windows, e por meio do qual usuários podem trocar mensagens de texto, imagem e vídeo. $\mathrm{O}$ apelo comercial desse produto, no ano de seu lançamento, foi a possibilidade de produzir informação de cunho íntimo e disponibilizá-la para um público seleto, por meio de uma espécie de chat privado ${ }^{2}$. Com o passar do tempo, novas versões do aplicativo foram lançadas e este mote baseado no segredo e na exposição seletiva das imagens e textos acabou cedendo lugar ao argumento de compartilhamento de instantes (RISSE, 2016). A própria página de venda do aplicativo na Google Play traz como slogan a frase: “A vida é mais divertida quando você vive cada momento :) Bom Snapping”.

A seguir, nas figuras 1a e 1b, apresentamos algumas capturas de tela feitas de um dispositivo móvel da página do aplicativo na Google Play, que demonstram alguns traços da linguagem adotada pelo aplicativo, evidenciada pela proposta dos filtros de tela disponíveis e

\footnotetext{
${ }^{2} \mathrm{O}$ símbolo do aplicativo é um contorno em forma de fantasma, no qual o usuário pode inserir imagens. $\mathrm{O}$ fantasma faz alusão ao anonimato e à possibilidade de divulgar informações de cunho pessoal sem ser notado ou visto por muitas pessoas, já que o tempo de visualização das mesmas é reduzido.
} 
emojis personalizados, um dos recursos que ficaram conhecidos como mais emblemáticos do serviço.

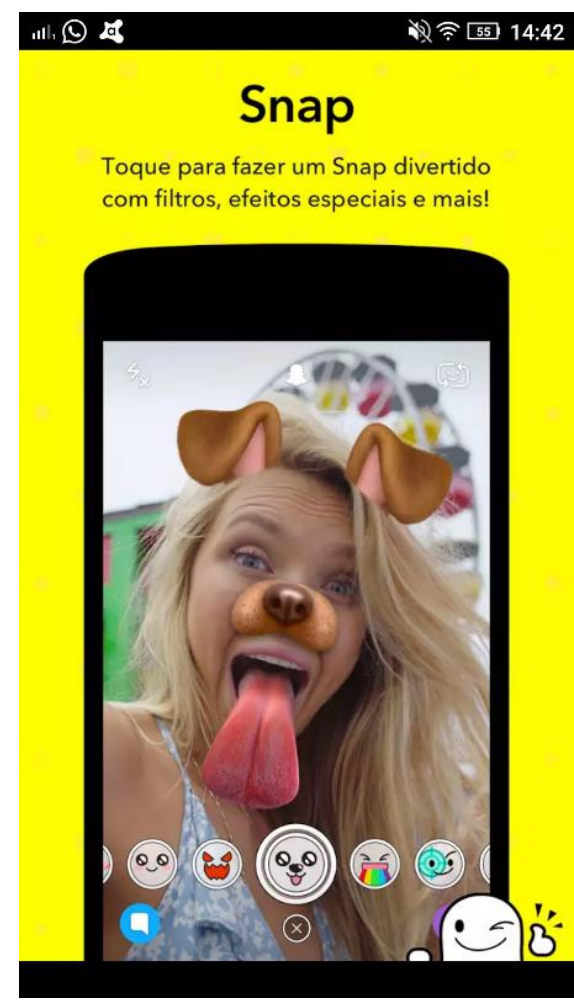

a

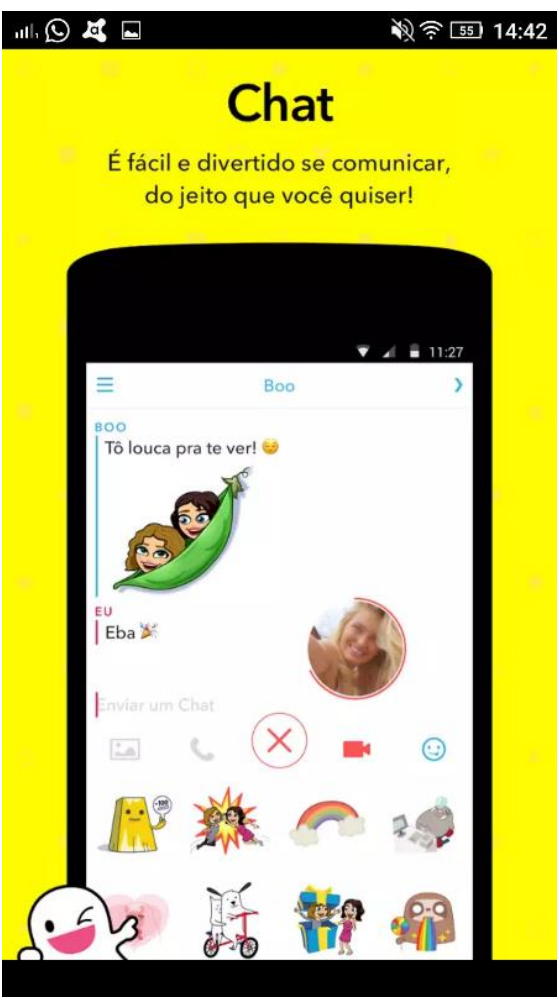

b

Figura 1: a e b

A lógica central de uso do aplicativo ocorre a partir das seguintes ações: cada usuário se torna produtor a partir do momento em que publicar no seu feed, chamado de "Minha História", um material imagético que pode ser produzido a partir de fragmentos de vídeos com duração de até 10 segundos ou imagens estáticas que podem ser expostas, também, até 10 segundos. Esses materiais ficam disponíveis para a visualização do público "que o segue" - usuários que escolheram fazer parte da rede de contatos desse indivíduo em questão durante um período de 24 horas, em uma linha do tempo que é atualizada ao passo que há a publicação de novos materiais. Essas imagens podem ser revistas inúmeras vezes ao longo deste tempo, basta recarregar a história do usuário por completo, até o momento em que elas são retiradas do ar, por atingirem seu tempo máximo de exposição.

Outra característica interessante é como o aplicativo simboliza a passagem do tempo e espacializa o montante de imagens postadas. Em versões anteriores - como as atualizações 9.29.3.0 e 10.4.5.0 - por exemplo, cada um dos usuários era identificado pelo nome e por um pequeno círculo composto por "fatias do tempo capturado", ou seja, por imagens que 
representavam as diversas ou a única produção audiovisual e fotográfica que o usuário podia ter feito dentro do período de 24 horas. Isso acontecia porque os sujeitos dispunham de capturas que podiam durar até 10 segundos, de modo que, ao longo do dia, um mesmo usuário podia acumular vários exemplares destas superfícies de 10 segundos, representadas no círculo por um frame cada. Hoje, a partir da versão citada no início deste parágrafo, o próprio aplicativo escolhe uma imagem média que possa representar todas as imagens postadas, congela o fluxo e se fixa em um acontecimento como mostrado na figura 2, ao lado esquerdo do nome dos usuários e do tempo desde que a última imagem foi postada.

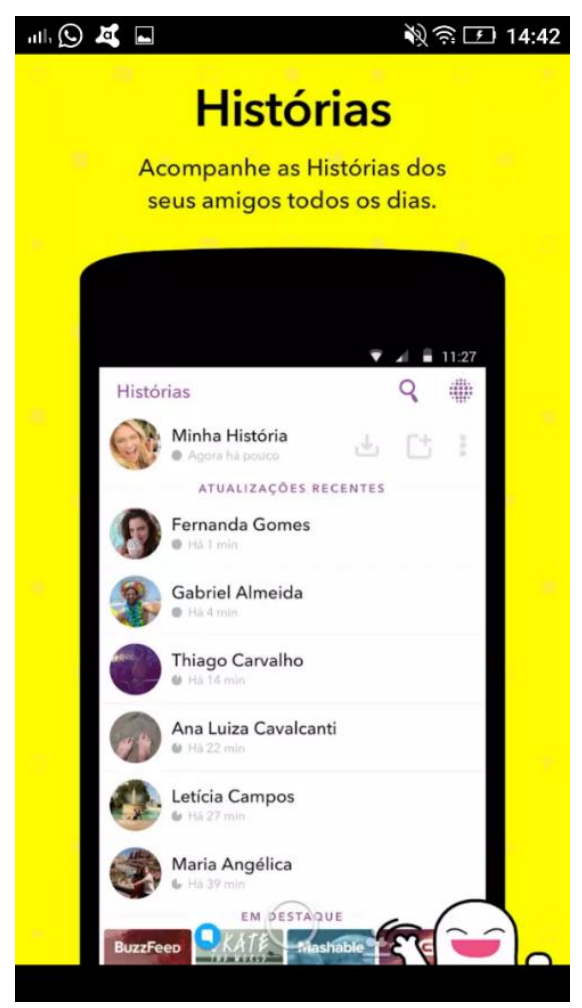

Figura 2: Feed Snapchat Fonte: Elaborado pela autora

Embora o Snapchat tenha perdido bastante espaço mercadológico para outros aplicativos, ele segue sendo uma iniciativa emblemática do modo de comunicar efêmero, pois desde o seu nome ${ }^{3}$, sua interface, até as imagens que gera, serviram de modelo para uma leva de outras experiências comunicacionais desse cunho efêmero. Nossa intenção com essa introdução ao aplicativo, não é de fazer um mergulho mais efetivo nos seus modos de

\footnotetext{
${ }^{3} \mathrm{O}$ verbo to snap possui uma ampla rede de significados, a maioria deles ligados à ideia de rapidez, de compartilhamento veloz e de pequenas ações ligadas também à velocidade, como quebrar algo por conta da pressa, ou tirar uma foto para registrar algo passageiro.
} 
funcionamento ou lógicas de ação, mas sim de incitar o entendimento de como ele está ligado com uma proposta de envolvimento com temporalidades, ou pelo menos com uma ideia sobre tempo construída nele e para o funcionamento dele próprio. Foi exatamente isso que nos levou a pensar que a efemeridade poderia se constituir como um construto não só do Snapchat, mas de um regime tecnocultural que incita modos de lidar e de registrar a passagem do tempo vistos não só na superfície das imagens e na interface do aplicativo, mas também no processo criativo do produtor e na sua própria relação com temporalidades, com os modos de armazenamento informacional, entre outros aspectos.

O fato das imagens serem disponibilizadas durante 24 horas e depois saírem de circulação $^{4}$, a fixação de um tempo máximo de duração dos vídeos, a sinalização constante da passagem do tempo nas postagens e, principalmente, a insistência em promover experiências efêmeras que permitam uma renovação constante dos dados - sistema de feed infinito - e a aproximação gradativa com uma promessa de instantaneidade, convoca-nos a pensar em uma comunicação voltada para uma temporalidade particular, pautada numa ideia de presente construída tecnoculturalmente, que é efêmera e que estabelece uma relação dialética com a efemeridade do ambiente digital.

Esse nome, Stories, vem do universo comercial, dos desenvolvedores da equipe de Mark Zuckerberg, programador e um dos fundadores da maior rede social do mundo, o Facebook, que viram uma lógica de funcionamento baseada na técnica o uso da câmera de celular, onde o protagonista conversa e se movimenta livremente, com um foco duplo direto em faces (selfies) e no que essas faces veem, direcionando o espectador às suas experiências; e a nomearam. No próximo tópico, entraremos no âmbito da efemeridade em si, mostrando como a enxergamos teoricamente enquanto qualidade. Este aspecto é importante, pois nos dá possibilidade de não só entender o que se passa na superfície empírica que trabalhamos aqui, o Stories, mas sim para que possamos pensar amplamente sobre o que a habita, o que dura dentro dela.

\footnotetext{
${ }^{4}$ É importante esclarecer que elas saem do circuito de consumo dos usuários, mas não podemos assegurar que elas somem dos sistemas operacionais dos aplicativos. Tanto é que ao aceitar os termos de adesão do serviço, os usuários também aceitam uma política de privacidade que é clara ao dizer que as informações podem ser armazenadas por um período de tempo maior que os snaps, ou seja, 24 horas. Informações coletadas da última política de privacidade, atualizada em 10 de janeiro de 2017 e disponível em: < https://www.snap.com/ptBR/privacy/privacy-policy/>.
} 


\section{A Efemeridade enquanto qualidade}

Delimitamos que é no âmbito da produção dos sujeitos comuns e de instituições, da expressiva relação homem-máquina, da natureza da internet, do imaginário digital e dos modos de lidar com a passagem do tempo que a problemática da efemeridade se constitui, como uma tentativa de pensar uma especificidade do contexto tecnocultural caracterizado pelo que Omar Calabrese (1988) chamou de Neobarroco: um panorama polifônico, descentralizado, no qual temos contato e dispersão de linguagens, mixagem de elementos e, uma saturação de informações que acabam agenciando os modos pelos quais lidamos com a experiência do tempo.

Aqui, a efemeridade se constitui como um devir, uma virtualidade, em termos bergsonianos, que perpassa uma multiplicidade de produções e iniciativas, realizando-se de formas diversas, diferenciando-se de si mesma (BERGSON, 2006) ao passo que se movimenta. Sendo assim, ela não é percebida aqui apenas como característica do imaginário tecnológico, enxergada quando nos referimos à velocidade e à volatilidade dos dispositivos e das produções digitais, mas sim como uma qualidade fundante que atravessa o meio digital em si e que se baseia na diferença para se constituir como tal. Chegamos a este conceito a partir do contato com a filosofia da diferença de Gilles Deleuze, ancorada fortemente nas contribuições de Henri Bergson. Esta corrente de pensamento é constituída a partir de dois eixos condutores, o metodológico e o ontológico. O primeiro se realiza na determinação das diferenças de natureza entre as coisas, passo essencial para o alcance do método intuitivo bergsoniano, a partir do qual se autentica na multiplicidade a coisa que estamos observando; já o segundo, dá-se na percepção da própria diferença como algo que possui natureza, permitindo ao sujeito lançar um olhar ontológico sobre ela. O que nos parece produtivo é pensar, em termos teóricos ${ }^{5}$, a partir do segundo eixo, procurando compreender a natureza da diferença que se dá na tecnocultura, especificamente no âmbito digital, como elemento constitutivo do que entendemos por efemeridade.

Intuímos que a qualidade efêmera é portadora de uma potência interessante para pensarmos tanto o meio digital quanto suas produções, de modo que a concebemos como duração. Ela é parte tensionadora da web, e do imaginário tecnológico, em última instância, pois estes enunciam-se por meio dos códigos de permanência, durabilidade e segurança, ao

\footnotetext{
${ }^{5}$ Neste momento falamos apenas em termos teóricos pela etapa do texto, mas a perspectiva metodológica da diferença também será acionada posteriormente, no tópico dedicado à proposta metodológica.
} 
passo que as lógicas que os regem são de outra natureza, descontínua, efêmera, que estimula a substituição (FISCHER, 2015), e a constante renovação daquilo que já foi, do eso há sido.

Este universo dúbio de aspectos foi visto também no campo das problematizações, já que o ponto de vista acerca da qualidade essencial do ambiente digital pode variar, saindo de um com a efemeridade como objeto central das observações, e indo para angulações e problematizações feitas vendo o aspecto memorial como qualidade que atravessa as novas mídias e o imaginário tecnológico. O estado da arte nos mostra uma gama de trabalhos e obras que versam sobre a memória como um agente constitutivo da internet ou sobre os rastros que essa qualidade deixa nas práticas, produções e lógicas digitais. Nesse sentido, destacamos a obra de alguns autores que pensaram a efemeridade do ambiente digital por meio de vieses diferentes, como o da identidade e performance (CARVALHO, 2012), (SENFT, 2015); da preservação digital (BEIGUELMAN, 2015), (FISCHER, 2015), entre outros. Mas, mesmo nestes estudos, encontramos os impasses paradoxais comuns ao tema e que configuram dualidades como "voyeurismo e narcisismo, privado e público, original e cópia, real e não real, espaço e tempo, poder e resistência, self e outro, humano e tecnologia, institucional e individual, sujeito e objeto", todas elas ratificando a contaminação da lógica binária, nativa do universo das máquinas que, por vezes, transborda para outros territórios, fazendo do nosso tempo e de espaços como a própria internet, regiões que abrigam tensionamentos dessas ordens, onde há a presentificação do passado por meio de diversos pontos como estes (WISE, 2012).

Acionamos Beiguelman (2015) como um exemplo do ponto de vista direcionado para a memória. No texto, a autora apresenta-nos uma interessante problematização que parte de uma arqueologia da estética da memória no campo da arte, recuperando diversas técnicas e modos de representação memoriais datados da Renascença e do Egito Antigo, que já ensaiavam o enlace das práticas artísticas com a memória. A autora faz um movimento de escavação para dar luz à pergunta central do texto que é "qual a estética da memória na era da digitalização da cultura?". Para ela, quase nenhuma palavra ganhou tanto o gosto popular quanto memória, conceito que transitou do campo das pesquisas neurocientíficas e históricas para se tornar um vocábulo norteador de aspectos básicos da vida cotidiana, tornando-se carta coringa quando o tema é armazenamento de informação. Além disso, ela pensa as formas pelas quais o passado pode ser acessado por meio das estratégias estéticas, como forma de ressuscitação, alcance e retomada. 
Podemos dizer que o Stories é uma superfície que movimenta estes aspectos memoriais, que muito falam sobre o ambiente digital e sobre a comunicação efêmera, tendoos em devir na sua natureza. Falaremos mais sobre isso no próximo tópico, dedicado a fazer uma observação mais verticazalizada do empírico em busca de algumas marcas estéticas e de lógicas de funcionamento que deem a ver os construtos temporais dos quais falamos.

\section{Stories, território de observação}

Como explicamos no primeiro tópico do artigo, o território empírico no qual identificamos possibilidades de apreensão e caracterização de marcas estéticas relacionadas aos construtos de tempo, é a imagem contemporânea, produzida para a internet, especificamente para o formato Stories. Esse é um entendimento sobre o formato, mas uma observação mais atenta, com uma visada dissecatória (KILPP, 2010), seria essencial para uma varredura de superfície e descoberta de lógicas intrínsecas às imagens. Além disso, pensamos que além da observação das imagens feitas para sumir é necessário um segundo movimento que é o entendimento acerca da interface que abriga esse material, já que é nela que grande parte das marcas efêmeras são espalhadas.

Diante dos Stories temos a possibilidade de um rico debate sobre um tempo construído midiaticamente e que passou por um processo gradativo de "fracionamento em instantes e instantaneidades" como afirma o filósofo francês Paul Virilio (1999, p. 57), e que não mais se atualiza em imagens solo, em imagens emblemáticas por natureza e que verticalizam suas potencialidades em poucas unidades, pelo contrário. As imagens que compõem a tendência Stories são conjunto, horizontalizam suas potências e são veículos de desfragmentação, levando a um estrato de quantificação da experiência que não tinha sido alcançado até então.

Ainda sobre a relação desse tipo de imagem com o tempo, trazemos a visão de André Parente (1993) sobre a sociedade de controle pós-industrial, transformada em obra há quase $25 \operatorname{anos}^{6}$. Nesse escrito, o autor nos apresenta a perspectiva sobre o paradigma capital do tempo, na qual, entende-se que, em algum ponto da modernidade, diversas esferas da vida social passam a incorporar valor simbólico e monetário às práticas e iniciativas que estejam

\footnotetext{
${ }^{6}$ Destacamos a importância de Imagem Máquina enquanto produção intelectual nacional que pensa a imagem e um estatuto imagético à frente de seu tempo. Como dissemos, a obra foi lançada em 1993, com um compilado de textos de diversos autores, e que, até hoje, reverbera de maneira intensa nos estudos da linha de pesquisa à qual integramos, e também nos outros grupos de pesquisa com os quais tivemos a oportunidade de fazer parte anteriormente.
} 
ligadas à ideia de velocidade, instantaneidade e consumo de instantes, dando vida a uma espécie de "maquinação do tempo" (p. 16). Esse conceito nos parece muito preciso e condizente com a nossa proposta de efemeridade enquanto um devir, pois ele convoca o debate sobre uma imagem que está além do paradigma de representação do passado (eso ha sido) e que se torna processo, veículo de processos de subjetivação, agenciamentos, e da criação de mundos.

É inútil, portanto, na tentativa de convencer-nos, de retornar até Copérnico e Galileu. $\mathrm{Ou}$, ainda, de retomar Einstein e Niels Bohr para concluir que, em matéria de temporalidade, o tempo não é mais inteiro, mas indefinidamente fracionado em quantos instantes, instantaneidades, quanto permitem as técnicas de comunicação e de telecomunicação (VIRILIO, 1999, p 57)

Sendo assim, temos diante de nós uma paisagem múltipla de imagens que subverte a operação da simulação tradicional, onde se fazia parecer que a imagem sempre existia em relação a uma realidade, originando a equação: "toda imagem (x) é uma imagem de (y), logo, imagem (x,y)" (ALLOA, 2015, p.13). A imagem digital, que ruma como soberana em direção a um futuro próximo, não depende mais da suplantação do real para existir e ter uma funcionalidade, ao invés disso, nutre-se da potencialidade que a ideia de presença lhe oferta. Uma imagem que atravessa oceanos para estabelecer uma conexão entre indivíduos, por exemplo, não se resume a ser um duplo do "real", mas transborda essas fronteiras, sendo algo, aquém de um referente, com o "poder de tocar o que está ausente tornando presente aquele que está distante” (2015, p. 10).

Parece-nos que, a perspectiva mais acertada em olhar para estes objetos não é mais a de separação entre um real e um simulado, mas uma tentativa de contemplar o dois, um misto, pois, de acordo com Weissberg (1993, p. 120), "não há mais virtual puro, mas o compacto real/virtual". Há então uma continuidade que nos afasta de pontos de chegada sobre um estatuto acerca dessa imagem, mas nos aproxima de uma concepção de caminho. A tese se localiza neste momento de passagem e se foca em uma superfície imagética que condensa essas questões sobre a capitalização das imagens e dispositivos que registram a passagem do tempo, uma cultura de compartilhamento de construtos principalmente de instantaneidade e na proliferação de dispositivos que são, materialmente, pontos de trânsito e passagem para todo esse fluxo de experiências.

No estágio atual da tecnocultura e da consciência de que o contágio osmótico entre o tecnológico e o cultural são impulsionadores de uma forma de comunicar, encontramo-nos 
com essa imagem que tem como elemento fulcral o aspecto da diferença - já citado na introdução deste projeto -, que movimenta, e que é basilar na proliferação não só imagética, mas informacional.

Podemos dizer que a produção contínua do novo se baseia na ideia de diferença entre os conteúdos e processos, de modo que tudo, a todo o instante, incita uma produção de evocação mista de presente e passado, convocados a partir das imagens e de outros tipos de informação. Isso se relaciona, sem dúvida, com os aparatos tecnológicos, com as possibilidades de uso que emergem dos mesmos, e as ambiências necessárias para o seu consumo. Todos esses aspectos circundam a criação de construtos, ao mesmo tempo em que são decisivos para determinar como essa imagem será visualizada. Pensemos no cinema e no que a máquina cinematográfica e a sua ambiência geram na experiência diante das imagens. Há uma composição de tela, uma escuridão programada e uma forte indução à imobilidade do espectador, que juntas, criam um contexto propício para o mergulho na temporalidade que o filme oferece. A cada cena, temos uma ideia de presente se realizando, mas pela imersão, o processo de assimilação dessa temporalidade se dá de forma mais orgânica, onde se degusta cada som e imagem.

Com a fotografia por outro lado, o processo de captação do olhar do espectador, segundo Roland Barthes (2003) acaba também por criar um próprio tempo, uma experiência de temporalidade que incita o movimento subjetivo, engendrando o que ele chama de imagem pensativa, uma imagem que demanda um olhar atento, que também convide a degustar as escolhas feitas por aquele que capturou a imagem. Nos dois casos, o do cinema e da fotografia, estamos falando sobre uma construção teórica que reconhecia essas imagens como parte de um sistema de representação, e no caso das imagens digitais? E no caso das imagens digitais feitas para sumir? Esses questionamentos que apontam para a natureza das imagens e também de seus usos são inspirados na pesquisa de Sonia Montaño (2015, p.71) sobre o YouTube e o Justin TV, na qual ela se perguntou: o que significava fazer login nesses territórios e se tornar um usuário? Segundo ela, essa adesão implica em:

Iniciar coleções de vídeos ou de comentários ou de amigos, processos todos mediados pelo vídeo. Significa também acionar uma geração espontânea de séries de vídeos como resposta a uma determinada busca e pensar o mundo através de palavras-chave ou etiquetas (MONTAÑO, 2015, p. 71). 
Da mesma forma, perguntamo-nos o que significa fazer uso do Stories e dos seus aplicativos? No que isso implica? Assim, chegamos em uma proposta de que há uma espécie de alforria da imagem em relação a um duplo e que temos a atribuição de uma capacidade de engendrar uma legião de pares, ou ainda, a criação de imagens que tem como ponto de partida outras imagens. Comprar a proposta de uma comunicação efêmera é exercer o papel dialético de produzir e consumir superfícies imagéticas que se realizam a partir de uma evocação constante de outras imagens, a todo o tempo. É como se elas não se bastassem e que suas funções se resumissem a exatamente isso: gerar mais imagens (LOPES, 2017) ${ }^{7}$ para que o ciclo de exibição siga ativo e cheio de fragmentos.

\section{Sobre as marcas efêmeras na tela}

Iniciamos com a figura $3^{8}$, um Stories postado. Nessa imagem podemos ver um exemplo do que seria uma imagem limpa, se não fosse a presença do software sinalizada em algumas marcas que indicam que ela pertence ao aplicativo, e de que está contida dentro da moldura Stories. Pensamos que essas marcas nem mesmo podem ser reconhecidas como rastro de algo, já que rastro é aquilo deixado despretensiosamente para trás, quase que por acidente e que, por consequência, revela algo. Nesse caso são sinais que, ao invés disso, indicam a presença dessa "segunda pele", o aplicativo.

\footnotetext{
${ }^{7}$ Frase proferida por Tiago Lopes, em reunião do Grupo de Pesquisa TCAv realizada em 17/04/2017.

${ }^{8}$ Tomamos a liberdade de não fazer os apontamentos a partir de uma ordem tão hierárquica envolvendo o que vem primeiro ou segundo nos usos do aplicativo, sendo assim, apesar desta não ser a interface primeira do Instagram, ela é apresentada agora na discussão porque possui uma potência para explicar este aspecto, mais do que outras.
} 


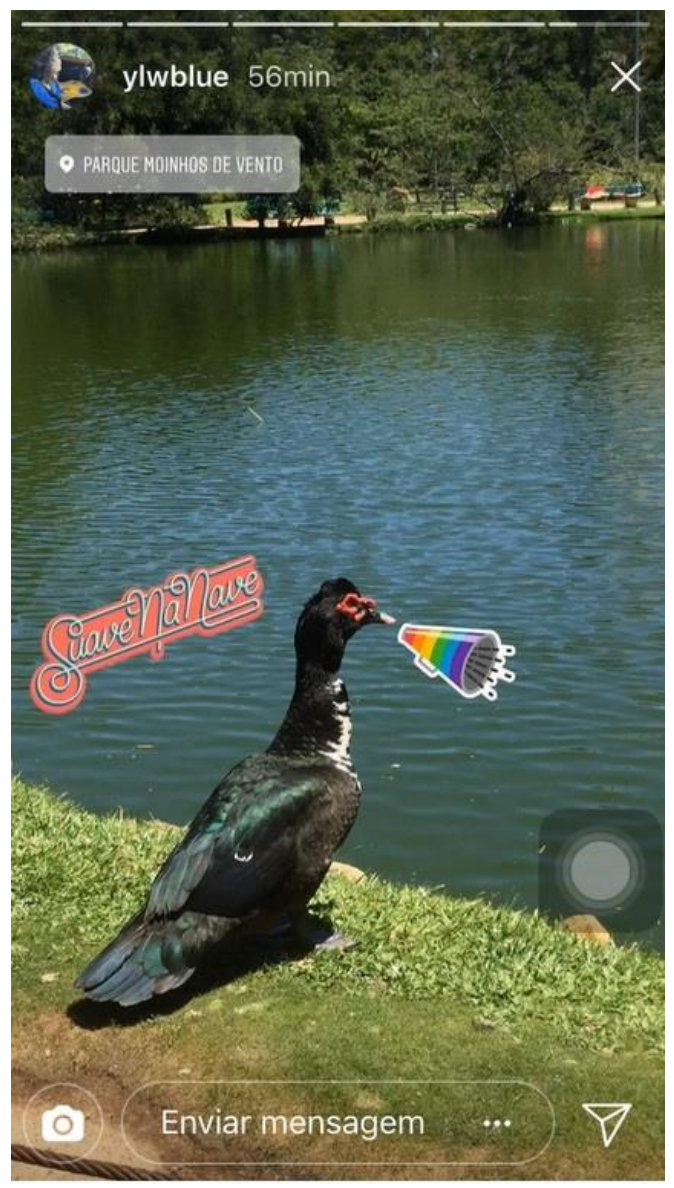

Figura 3 - Stories 1

Fonte: Elaborado pela autora

A imagem base desse Stories é o que poderia ser entendido por imagem limpa (uma fotografia de uma vista de um parque, sem nenhum tipo de informação sobreposta à sua superfície), se não fosse a interface fixa do Stories que a encobre, composta pela barra inferior e superior, e as escolhas adicionais de elementos feitas pelo usuário, como: os "stickers" (adesivos) suave na nave e megafone (adesivo lançado para a campanha de apoio à causa LGBT e que permaneceu no quadro fixo do aplicativo), e o sinalizador de localização, a partir do qual podemos ver que a imagem pode ter sido feita ${ }^{9}$ no Parque Moinhos de Vento, em Porto Alegre.

Essas sobreposições configuram uma montagem espacial pensada para dar ao produtor e ao consumidor da imagem, o máximo de informações possíveis sobre a experiência de quem

\footnotetext{
${ }^{9}$ Falamos nesse tom de possibilidade pelo fato do Stories também aceitar imagem que venham de arquivo, além de permitir que o usuário possa procurar o local que quer indexar a imagem, mesmo que não esteja nele naquele instante. Sendo assim, essa fotografia pode ter sido feita em outro lugar, em um outro dia e mesmo assim, ser postada enquanto atual, fazendo valer nossa proposta de que essas imagens são veículos de construtos de tempo real.
} 
a posta, mantendo as marcas que tendem a consolidar o construto de tempo real, ou seja. Esses elementos estão localizados na barra fixa do aplicativo, nas extremidades da imagem, e ao serem somadas às marcas de livre escolha do usuário expandem os limiares do construto de tempo para um construto de experiência compartilhada ${ }^{10}$, montado a partir de indicativos sobre a experiência (hora, local, avaliação da experiência por meio de elementos adicionais), além da própria imagem que serve como um referencial do acontecimento, um testemunho, deixando-a mais coletiva do que individualizada. Sendo assim, estamos falando de uma construção midiática que mescla elementos digitais e elementos orgânicos (concretos), de modo a criar não só uma estética que tende a nos colocar dentro deste universo híbrido, mas também que agencia sentidos e sugere, por meio destas estratégias adicionais, que ao olhar as imagens do mundo por meio do guarda-chuva Stories, ampliam-se as potencialidades relacionais daqueles que participam, sejam eles os indivíduos, as máquinas, os locais e o próprio tempo.

Isso acontece pelo fato destas imagens não serem mais da ordem da representação e da expectação unicamente e sim portadoras dessa quase vocação de promover um universo compartilhado entre quem mostra e quem assiste. Esse universo de trocas não surge com essa configuração imagética atual, mas agora se condensa de uma forma única, justamente pela potência de trânsito que as mídias digitais possuem. Sendo assim, estas imagens são potência de movimento, de engajamento, de comunicação, pela sua natureza de ser imagem, impressa também nas marcas de presença dos softwares que nos convidam a todo o instante a participar.

Diante disso, vamos descer mais uma camada sobre o construto de tempo, apontado desde o início do texto como um dos elementos centrais nessa constituição do efêmero. Ele aparece nessa camada também por meio das marcações na interface: a primeira, e mais direta, a indicação do tempo que o Stories foi postado. No caso dessa imagem, temos o tempo de veiculação marcado em 56 minutos antes da nossa visualização, informação dada com uma linguagem que reforça a ideia de que o que importa sobre a imagem é sua proximidade com o presente daquele que a consome, a que distância dessa temporalidade ela está. Além disso,

\footnotetext{
${ }^{10}$ Não falamos em uma experiência compartilhada porque nos interessa falar sobre o que e como as imagens constroem essa relação, da mesma forma como entendemos o construto de tempo real, já mencionado anteriormente. Os arranjos que promovem esses encontros midiáticos são o foco da nossa atenção.
} 
temos as marcações dos Stories, as linhas que ficam bem acima na barra fixa, que nesse caso, totalizam seis, indicando que seis imagens (estáticas ou não), foram postadas por esta usuária.

$\mathrm{Na}$ última barra ${ }^{11}$, é possível notar que ela corresponde à imagem que capturamos na tela e que ela ainda tinha um tempo de exibição restante considerável (estas imagens possuem o máximo de 5 segundos de exibição para imagens estáticas e 15 para vídeos), já que no aplicativo, ao passo que essa vida de exibição da imagem passa, a barra temporal vai se enchendo e passando para outra. Este é um interessante conceito sobre a representação da passagem do tempo para um aplicativo que o faz puramente por meio das imagens, pois ele sugere, o tempo todo, que se trata mesmo de algo efêmero, tanto na sua matéria prima, quanto na sua forma de funcionamento. No momento em que a barra estiver completa, o Stories vai acabar, e então somos colocados diante da figura quase que simbólica de um tempo que se esvai, mesmo que esteja sendo preenchido por algo, como indica a interface. Talvez ele esteja sendo estopado pela exibição de algo, durando até que se esgote e renasça em outra peça, em um duplo seu, outra imagem.

Outra percepção se deu em um território quase que camuflado pelo aplicativo, a estética de transição dentro do fluxo do Stories. Ao todo identificamos dois modos com os quais a passagem de uma imagem para outro se dá, a primeira se comporta de forma discreta reproduzindo um mecanismo parecido com o adotado na televisão, com os comerciais, onde os vemos passando, um após a outro, sem nenhuma inicialização ou finalização necessária para o entendimento da mudança de uma superfície para outra. A segunda vertente, por outro lado, é mais aparente, ela é resultado do ato incisivo de mudança, necessariamente acionado pelo usuário. A imagem que está na tela e quer ser "passada" precisa ser "puxada" por um movimento de transição que, quando acionado pelo usuário, simula a passagem de uma aresta na tela, como se estivéssemos vendo um prisma triangular de imagens em que cada face representa os Stories de cada canal, e quando recebe esse impulso de mudança, feito pelo toque na tela (da direita para a esquerda quando se quer ir pro Stories seguinte, e da esquerda para a direita, quando se quer retornar ao Stories anterior) muda para a próxima face do prisma, como podemos ver na figura 4 , na qual percebemos claramente a presença do prisma por conta dos espaços em branco que ficam abaixo das imagens, dando a ver as bordas desse "sólido imagético".

\footnotetext{
${ }^{11}$ Além disso, como já citado na introdução deste documento, estas marcações também indicam que esta imagem possui até 24 horas de vida no aplicativo e que cada Stories pode durar até 15 segundos.
} 
revista do programa de pós-graduação em comunicação social faculdade de comunicação e artes da PUC Minas

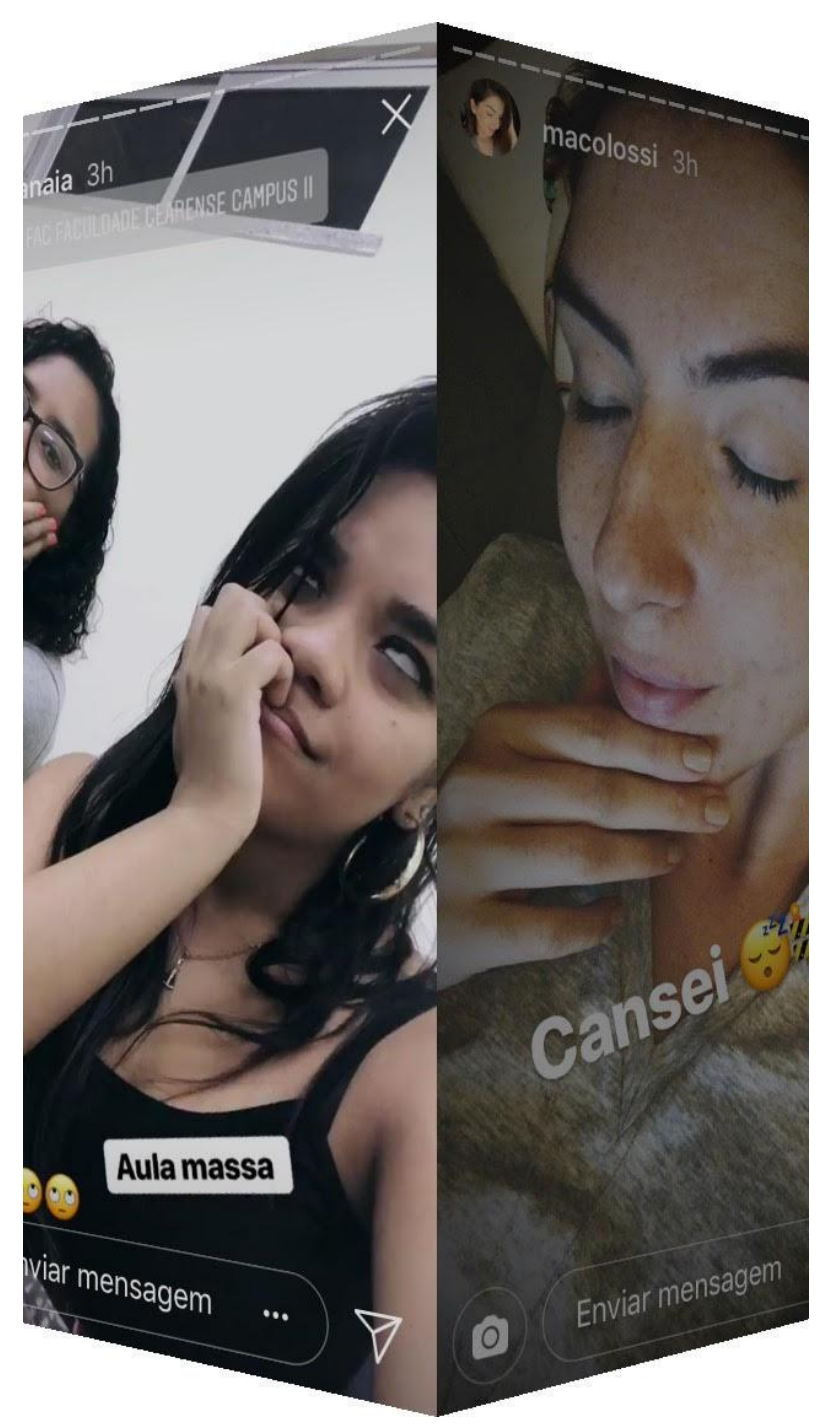

Figura 4 - Prisma Imagético

Fonte: Elaborado pela Autora 
$\mathrm{Na}$ barra inferior temos uma área dedicada à camada interacional da interface. Nela, o usuário que consome as imagens pode se comunicar com outros integrantes da rede, mandando-lhes a imagem que ele vê, ou ainda, mandando mensagens diretas para aquele que a postou. Vale esclarecer que esta resposta à imagem, pode ser feita não apenas por meio de texto, mas também com outra imagem. Para isso, basta acionar o ícone da câmera fotográfica, localizado no lado esquerdo da tela. Ao tocá-lo, o usuário é levado direto para esta função no celular (câmera), podendo criar algo em qualquer um dos sete formatos imagéticos ofertados pelo aplicativo, são eles: ao vivo, normal, boomerang, superzoom, stop motion, rebobinar e mãos livres.

- $\quad$ Ao vivo - Trata-se da captação e veiculação ao vivo de períodos de tempo à escolha do produtor. Após a transmissão, o vídeo fica disponível para a visualização por até 24 horas, tornando-se um Stories com um tempo de exibição livre;

- $\quad$ Normal - Trata-se da captação em foto ou vídeo. A diferença entre este modo e o modo "mãos livres" é que neste o produtor, ao filmar, necessita estar com o botão de gravar pressionado para que seja realizada a captura. Por este motivo, ele é mais utilizado para capturas fotográficas do que audiovisuais;

- Boomerang - Trata-se da captação de frames em sequência que geram uma espécie de gif animado do evento em foco, que se repetem por 3 loopings temporais, indo e voltando;

- $\quad$ Superzoom - Trata-se da captação em vídeo, com um movimento de câmera e trilha sonora já condicionados pelo aplicativo. No lançamento desse recurso, os usuários tinham apenas uma opção de captura, o zoom dramático. Ele era composto por um movimento de três níveis de zoom na tela, acompanhados de sons de metais, que incitam o sentido de surpresa ou atenção para a imagem. Uma referência para o entendimento de que imagem estamos falando é a filmografia de Quentin Tarantino, com sua marca fílmica de dramaticidade com movimentos de câmera rápidos e sons como este. Atualmente, a cartela do superzoom se expandiu e ganhou mais três movimentos: Batidas, adiciona uma música eletrônica, luzes e movimentos que simulam um ambiente dançante à imagem; Programa de $\mathrm{TV}$, cria um efeito de vinheta arroxeado que simula a trilha de finalização de cenas de novelas e filmes, e; Bounce, efeito no qual a imagem e o som simulam efeitos de uma mola, lembrando as onomatopeias de desenhos animados ou produções cômicas; 
- $\quad$ Stop Motion - Trata-se da captação de fotos que posteriormente serão agrupadas pelo aplicativo, ganhando uma montagem em stop motion, com menos frames por segundo do que o normal;

- $\quad$ Rebobinar - Trata-se da captação de vídeos que são veiculados de trás para a frente;

- Mãos Livres - Trata-se da captação de vídeos sem que o produtor precise manter pressionado o botão de gravar. Esse recurso é utilizado com mais intensidade pelos Instagrammers (profissionais que usam o Instagram como fonte de veiculação dos seus serviços), já que o ato de segurar o celular por um longo período de tempo, tendo que apertar o botão central de gravação, causa um desconforto manual. Em outras palavras, possui a mesma funcionalidade que o recurso "normal", mas deixa indícios de que foi pensado diante de percepções sobre a prática do aplicativo, de uma necessidade dos usuários.

Todos estes recursos foram lançados pelo Instagram em versões de atualizações diferentes, podendo ser retiradas pelo aplicativo e substituídas por outras a qualquer momento. Até a captura deste material, o Instagram estava com sua última atualização feita no dia 20 de setembro de 2017. Ao fazer a observação do aplicativo desde 2015 (RISSE, 2016; 2017) podemos dizer que, o grande investimento do aplicativo são as possibilidades de captação de imagem e com elas, as de interação, e o mais curioso é que estes aspectos de "sucesso" do Instagram, duram em outros aplicativos observados por nós. O Snapchat, por exemplo, passou pelo mesmo processo de desenvolvimento, não tendo grandes mudanças na interface, desde o seu lançamento em 2011, contribuindo para a nossa primeira inferência sobre os aspectos que compõem o cenário apresentado até aqui: o que muda, as reais diferenças nos serviços não dizem respeito à primeira imagem, mas sim à segunda imagem, ou seja, às funcionalidades, aos Stories. É este formato que engendra o movimento nos aplicativos, principalmente pelas formas de captação de imagens. As ofertas funcionais movimentam as formas com as quais os produtores podem contar suas histórias, indo além dos formatos tradicionais de imagem e vídeo e atualizando os modos como o efêmero pode ser contado. 


\section{Considerações finais}

Este artigo teve como foco trazer à tona um debate sobre como são configurados alguns construtos de tempo nas novas mídias. Esse conceito, construto, foi acionado aqui de forma a dar a ver as lógicas constitutivas das imagens, com as quais se formam sentidos, imaginários, práticas e até mesmo, experiências, como a de lidar com a passagem do tempo. $\mathrm{O}$ Stories é um território no qual essa potência fica evidenciada, justamente pela sua maneira efêmera de "contar histórias". Embora saibamos que a Comunicação em si tem a efemeridade como característica central, decidimos olhar para como o sentido de registro de atualiza na contemporaneidade, permeado por lógicas efêmeras que surgem com o atual estágio da técnica.

A partir dos exemplos trazidos foi possível perceber como se constroem os sentidos de temporalidade, essencialmente na interface do aplicativo que abriga o Stories, o Instagram, e também no próprio desenrolar da imagem que possui características marcantes que tendem a revelar a presença deste devir efêmero, como: a duração limitada da vida útil, indo até 24 horas, a duração limitada de exibição, indo 15 segundos, entre outros aspectos. Percebemos que iniciativas como o Snapchat e o Instagram, colocam-se na contramão de, por um lado, uma onda de aplicativos de sociabilidade que oferecem possibilidades de visualização ilimitadas em forma de arquivo, e por outro, das mídias tradicionais como a TV e o cinema, que funcionam pela lógica da massificação e da imagem como superfície que demanda um olhar mais atento. Disponibilizando as imagens por apenas 24 horas, essas iniciativas acabam por agenciar experiências por meio de uma superfície imagética de dispersão que incita um olhar mais nervoso. Acreditamos que o que ela mais suscita é o olhar passageiro, interessado por um tempo cada vez mais próximo do presente, do instantâneo.

\section{Referências}

ALLOA, Emmanuel (org). Pensar a imagem. Belo Horizonte: Autêntica Editora, 2015. BEIGUELMAN, Giselle. Corrupted Memories: The Aesthetics of Digital Ruins and the Museum of the Unfinished. Helena Barranha, p. 55. 2015. Disponível em <https://www.academia.edu/13212743/CORRUPTED_MEMORIES_THE_AESTHETICS_O 


\section{F_DIGITAL_RUINS_AND_THE_MUSEUM_OF_THE_UNFINISHED> (Acesso} julho/2015).

BARTHES, Roland. A câmara clara: nota sobre a fotografia. In: Pensar a imagem. Belo Horizonte: Autêntica Editora, 2015.

BENJAMIN, Walter. Obras escolhidas III: Charles Baudelaire um lírico no auge do capitalismo. São Paulo. Brasiliense, 1989.

BERGSON, Henri. Cartas, conferências e outros escritos. São Paulo: Abril Cultural, 1979. . Matéria e memória. 2. ed. São Paulo: Martins Fontes, 1999.

CALABRESE, Omar. A idade neobarroca. São Paulo: Martins Fontes, 1988.

FISCHER, Gustavo. "The Restart Page": Observações sobre Construtos de Memória no Terreno da Web. XXXVIII Congresso Brasileiro de Ciências da Comunicação: Rio de Janeiro, 2015. Disponível em: <

http://portalintercom.org.br/anais/nacional2015/resumos/R10-3198-1.pdf $>$.

FISCHER, Gustavo. Do audiovisual confinado às audiovisualidades soterradas em interfaces enunciadoras de memória. In: Tecnocultura audiovisual: temas, metodologias e questões de pesquisa. Porto Alegre: Sulina, 2015.

FLUSSER, Vilém. O mundo codificado. São Paulo: Cosac Naify, 2007.

FLUSSER, Vilém. O universo das imagens técnicas: elogio da superficialidade. São Paulo: Annablume, 2008.

KILPP, Suzana. Ethicidades televisivas. Sentidos identitários na TV: moldurações homológicas e tensionamentos. São Leopoldo: Editora Unisinos, 2003. MONTAÑO, Sonia. Plataformas de vídeo: apontamentos para uma ecologia do audiovisual da web na contemporaneidade. Porto Alegre: Sulina, 2015.

RISSE, Lorena. Da natureza da vida à natureza do vídeo: um estudo de vlogs que operam sobre a subjetividade publicizada. 150 f. Dissertação. (Mestrado em Comunicação) - Universidade Federal do Rio Grande do Sul, Faculdade de Biblioteconomia e Comunicação, 2014.

RISSE, Lorena. Construtos de tempo real: modos de agir da qualidade efêmera na contemporaneidade. In: XXXIX Congresso Brasileiro de Ciências da Comunicação, 2016, São Paulo, 2016. 
RISSE, Lorena. A efemeridade na contemporaneidade: escavações da tendência Stories em aplicativos de imagens feitas para sumir. In: XXXX Congresso Congresso Brasileiro de Ciências da Comunicação, 2017, Curitiba, 2017.

WISE, J. Macgregor. New Visualities, New Technologies: The New Ecstasy of

Communication. Disponível em <

http://web.a.ebscohost.com/ehost/ebookviewer/ebook/ZTAwMHh3d19fNTA3NTk2X19BTg2

?sid=3ea1478c-b9f3-48ee-9fb0-

55fbd7c93320@ sessionmgr4003\&vid=0\&format=EB\&rid=1>

VIRILIO, Paul. O resto do tempo. Revista FAMECOS, Porto Alegre. $\mathrm{n}^{\circ}$ 10. Trad. Juremir Machado da Silva, 2009. Disponível em: -

$\langle$ http://revistaseletronicas.pucrs.br/ojs/index.php/revistafamecos/article/viewFile/3029/2307>. WEISSBERG, Jean-Louis. Real e virtual. In: PARENTE, André (Org). Imagem máquina. Rio de Janeiro: Ed. 34, 1999. 